\title{
HUBUNGAN ANTARA FAKTOR-FAKTOR RESIKO CEREBRO-KARDIOVASKULER DENGAN KEJADIAN VERTIGO DI RSU ANUTAPURA PALU TAHUN 2018
}

\author{
Inri Hardyanti ${ }^{1}$, Wijoyo Halim ${ }^{1 *}$, Masita Muchtar ${ }^{1}$ \\ ${ }^{1}$ Program Studi Pendidikan Dokter, Fakultas Kedokteran Universitas Alkhairat, Jl. Diponegoro No. 39 \\ Palu 94221, Sulawesi Tengah, Indonesia \\ "Corresponding author: Telp: +628124245438 email: wijoyoneuro@gmail.com
}

\begin{abstract}
ABSTRAK
Vertigo merupakan keluhan tersering di unit gawat darurat dengan etiologi sederhana maupun kompleks yang sering overlapping. Angka kejadian vertigo setiap tahunnya mengalami peningkatan. Vertigo dapat menjadi keluhan utama ataupun satu-satunya pada pasien strok ataupun jantung koroner. Gangguan cerebro-kardiovaskuler juga diperkirakan terjadi pada 3-4\% pasien vertigo. Deteksi dan pengobatan awal sangat dibutuhkan untuk pencegahan disabilitas dan kematian. Pasien vertigo memiliki resiko lebih besar terkena strok dan jantung koroner karena beberapa fakotor resiko yaitu hipertensi, diabetes mellitus, dan dislipidemia, sehingga harus dilakukan pemeriksaan neurologis yang komprehensif, survei terhadap faktor resiko, dan follow up secara regular selama beberapa tahun setelah menerima pengobatan vertigo. Penelitian ini bertujuan untuk mengetahui hubungan antara hipertensi, diabetes melitus, dan dislipidemia dengan kejadian vertigo. Metode penelitian ini bersifat analitik observasional dengan design case control study pengambilan sampel dilakukan secara consecutive sampling. Pengumpulan data faktor risiko dilakukan dengan cara wawancara menggunakan kuesioner dan case report pada kedua kelompok pasien. Dilakukan uji Chi-Squar pada batas kemaknaan $\alpha=5 \%$ melalui program SPSS. Hasil penelitian menunjukkan Kejadian vertigo berhubungan dengan hipertensi ( $\mathrm{p}=0,018$; OR 4,753), dengan diabetes mellitus ( $\mathrm{p}=0,020$; OR 3,032). Belum dapat dibuktikan hubungan yang bermakna dengan dislipidemia ( $\mathrm{p}=0,844$; OR 0,655). Sehingga dapat disimpulkan bahwa ada hubungan kejadian vertigo dengan hipertensi dan diabetes mellitus di RSU Anutapura Palu Tahun 2018.
\end{abstract}

Kata Kunci : Vertigo, Kejadian Vertigo, Cerebro-kardiovasculer.

\section{ABSTRACT:}

Vertigo is the most common complaint in an emergency unit with a simple and complex etiology that is often overlapping. The incidence of vertigo increases every year. Vertigo can be the main or only complaint in stroke patients or coronary heart disease. Cerebro-cardiovascular disorders are also estimated to occur in 3-4\% of vertigo patients. Early detection and treatment is needed for prevention of disability and death. Vertigo patients have a greater risk of stroke and coronary heart disease due to several risk factors, namely hypertension, diabetes mellitus, and dyslipidemia, so a comprehensive neurological examination, risk factors survey, and regular follow-up for several years after receiving treatment for vertigo must be done. This study aims to determine the relationship between hypertension, diabetes mellitus, and dyslipidemia with the incidence of vertigo. The method of this research is analytic observational with case control design. The study of sampling is done by consecutive sampling. Risk factor data collection is done by interviewing questionnaires and case reports in both groups of patients. Chi-Squar test was carried out at the significance limit $\alpha=5 \%$ through the SPSS program.

The results showed the incidence of vertigo was associated with hypertension ( $p=0.018 ;$ OR 4.753), with diabetes mellitus ( $p=0.020 ;$ OR 3.032). There is no evidence of a significant association with dyslipidemia ( $p=0.844$; OR 0.655). So it can be concluded that there is a relationship between the incidence of vertigo with hypertension and diabetes mellitus in Anutapura Palu Hospital in 2018.

Keywords: Vertigo, Occurrence of Vertigo, Cerebro-cardiovascular. 


\section{PENDAHULUAN}

Vertigo merupakan gejala umum yang dikeluhkan lebih dari 90 juta orang di Amerika. Vertigo terjadi pada sekitar $32 \%$ kasus, dan sampai dengan $56,4 \%$ pada populasi orang tua. Di Indonesia vertigo terjadi pada $15 \%$ dari keseluruhan jumlah penduduk. ${ }^{1,2,3}$ Vertigo dapat menjadi keluhan utama ataupun keluhan satu-satunya pada pasien strok ataupun jantung koroner. Gangguan cerebro-kardiovaskuler juga diperkirakan terjadi pada $3-4 \%$ pasien vertigo. ${ }^{4,5}$

Cerebrovaskuler didefinisikan sebagai gangguan fungsi otak yang timbul secara mendadak, berlangsung selama 24 jam atau lebih, yang diakibatkan oleh gangguan peredaran darah di otak. ${ }^{6,7}$ Di Amerika, Cerebrovaskuler merupakan penyakit neurologi penyebab kematian tersering ketiga dan merupakan penyebab kecacatan nomor 1 setelah penyakit jantung dan kanker. Angka kematian akibat Cerebrovaskuler terus mengalami peningkatan setiap tahunnya, bukan hanya terjadi pada orang orang berusia lanjut, tetapi juga pada usia pertengahan (4050 tahun), yang mana pada usia inilah orang berada dalam usia aktif dan produktif. ${ }^{8,9,10}$ Ada beberapa faktor resiko Cerebrokardiovaskuler yaitu : hipertensi, diabetes mellitus, dyslipidemia. Dimana pada orang orang yang mengalami vertigo lebih beresiko mengalami strok dan jantung coroner akibat dari faktor resiko cerebro-kardiovaskuler tersebut.

Menurut data Riset Kesehatan Dasar pada tahun 2013, prevalensi di Indonesia 12,1 per 1.000 penduduk. Prevalensi penyakit Cerebro-kardiovaskuler di Indonesia pada tahun 2013 yang tertinggi terdapat di Sulawesi Selatan sebanyak 17,9\%, D.I.Yogyakarta sebanyak 16,9\%, dan Sulawesi Tengah sendiri sebanyak 16,6\%, dan Jawa Timur sebanyak $16 \% .^{2}$
Berdasarkan data yang didapatkan dari RSU Anutapura Palu jumlah pasien vertigo yang datang berobat pada tahun 2014 mencapai 480 pasien, pada tahun 2015 mencapai 410 pasien, dan pada tahun 2016 mencapai 458 pasien. Dan pada tahun 2017 pasien vertigo yang datang berobat mencapai 529 pasien. Dapat disimpulkan bahwa angka kejadian vertigo di RSU Anutapura Palu pada ahun 2015 mengalami penurunan, tetapi pada tahun 2016 hingga 2017 mengalami peningkatan.

Belum banyak penelitian mengenai hubungan antara faktor resiko cerebrokardiovaskular dengan kejadian vertigo serta berdasarkan uraikan diatas penulis terdorong untuk mengadakan penelitian hubungan antara faktor resiko cerebro-kardiovaskular dengan kejadian vertigo pasien di RSU Anutapura Kota Palu Tahun 2018.

\section{METODOLOGI}

Penelitian ini bersifat analitik dengan pendekatan case control. Penelitian ini dilakukan pada bulan April - Juni tahun 2018 dilakukan di Poliklinik Saraf RSU Anutapura Kota Palu. Populasi penelitian adalah seluruh pasien cerebro-kardiovaskular di Poliklinik saraf RSU Anutapura Palu pada tahun 2018. Subyek diambil dari pasien di Poliklinik saraf RSU Anutapura Palu yang memenuhi kriteria.

Menentukan besar sampel dengan menggunakan rumus analitik kategorik tidak berpasangan

$$
\begin{aligned}
& n 1=n 2 \\
& =\left(\frac{Z \alpha \sqrt{2 P Q}+Z \beta \sqrt{P 1 Q 1+P 2 Q 2}}{P 1-P 2}\right)^{2}
\end{aligned}
$$



P1- P2 : selisih proporsi minimal yang dianggap bermakna
P1 : proporsi pada kelompok yang nilainya merupakan judgement peneliti.
Q1 : 1- P1
$\mathrm{P} \quad$ : proporsi total $=(\mathrm{P} 1+\mathrm{P} 2) / 2$
$\mathrm{Q} \quad: 1-\mathrm{P}$
$n 1=n 2=38,13$ (dibulatkan menjadi 38)

Teknik pengambilan sampel yang digunakan dalam penelitian ini adalah NonProbability Sampling, Yaitu Consecutive Sampling dengan mengambil penderita cerebro-kardiovaskuler yang mengalami vertigo sebagai kasus dan penderita cerebrokardiovaskuler yang tidak mengalami vertigo sebagai kontrol, yang berada di Poliklinik Saraf RSU Anutapura yang memenuhi kriteria penelitian dan bersedia diikutkan dalam penelitian sampai jumlah subyek terpenuhi.

Didapatkan sampel dalam penelitian adalah 38 kasus dan 38 kontrol. Sehingga sampel yang dibutuhkan pada penelitian ini adalah 76 .

Kriteria inklusi Case

a. Penderita cerebro-kardiovaskular yang mengalami gejala vertigo.

b. Laki laki maupun perempuan. c. Berusia $>15$ tahun.

d. Setuju ikut penelitian tanpa paksaan.

Kriteria eksklusi Case

a. Penderita cerebro-kardiovaskular yang tidak sadar.

b. Tidak dapat berkomunikasi.

Kriteria inklusi Control

a. Penderita cerebro-kardiovaskular.

b. Laki laki maupun perempuan.

c. Berusia $>15$ tahun.

d. Setuju ikut penelitian tanpa paksaan.

Kriteria eksklusi Control

a. Penderita cerebro-kardiovaskular yang tidak sadar.

b. Tidak dapat berkomunikasi.

Analisis data yang digunakan adalah analisis bivariat dengan metode chi square. Metode ini digunakan untuk mencari hubungan dan membuktikan hipotesis dua variable. Data diolah dengan menggunakan perangkat lunak komputer program SPSS 22.0.

\section{HASIL DAN PEMBAHASAN}

a. Hubungan hipertensi dengan vertigo

Untuk mengidentifikasi hubungan hipertensi dengan vertigo, dilakukan crosstabulasi dan dihitung nilai $\mathrm{P}$ berdasarkan uji Chi-Square.

Tabel 1. Hubungan Hipertensi dengan Vertigo di RSU Anutapura PaluTahun 2018.

\begin{tabular}{|c|c|c|c|c|c|c|}
\hline \multirow{3}{*}{ Hipertensi } & \multicolumn{2}{|c|}{ Pasien Cerebro-Kardiovaskuler } & \multirow{3}{*}{$\mathrm{P}$} & \multirow{3}{*}{ OR } & \multirow{2}{*}{\multicolumn{2}{|c|}{$\mathrm{CI}$}} \\
\hline & & & & & & \\
\hline & $\begin{array}{c}\text { Mengalami } \\
\text { vertigo (n \%) }\end{array}$ & $\begin{array}{c}\text { Tidak } \\
\text { Mengalami } \\
\text { Vertigo (n \%) }\end{array}$ & & & Lower & Upper \\
\hline $\mathrm{Ya}$ & $\begin{array}{c}35 \\
(92,1 \%)\end{array}$ & $\begin{array}{c}27 \\
(71,1 \%)\end{array}$ & & & & \\
\hline Tidak & $\begin{array}{c}3 \\
(7,9 \%)\end{array}$ & $\begin{array}{c}11 \\
(28,9 \%)\end{array}$ & 0,018 & 4,753 & 1,206 & 18,738 \\
\hline Total & $\begin{array}{c}38 \\
(50,0 \%) \\
\end{array}$ & $\begin{array}{c}38 \\
(50,0 \%) \\
\end{array}$ & & & & \\
\hline
\end{tabular}

Dari tabel diatas dapat dilihat bahwa ada hubungan yang bermakna $(p<0.05)$ antara hipertensi dengan vertigo. Hipertensi merupakan faktor resiko terjadinya vertigo dengan Odd Ratio 4,753. Menunjukkan bahwa 
MEDIKA ALKHAIRAAT : JURNAL PENELITIAN KEDOKTERAN DAN KESEHATAN 1(1): 17-22

e-ISSN: 2656-7822

hipertensi 4,7 kali lebih mempunyai peluang terjadinya vertigo.

b. Hubungan Diabetes

Mellitus

Dengan Vertigo

Tabel 2. Hubungan Diabetes Mellitus Dengan Vertigo di RSU Anutapura Palu Tahun 2018.

\begin{tabular}{|c|c|c|c|c|c|c|}
\hline \multirow{3}{*}{$\begin{array}{l}\text { Diabetes } \\
\text { Mellitus }\end{array}$} & \multicolumn{2}{|c|}{ Pasien Cerebro-Kardiovaskuler } & \multirow{3}{*}{$\mathrm{P}$} & \multirow{3}{*}{ OR } & \multirow{2}{*}{\multicolumn{2}{|c|}{$\mathrm{CI}$}} \\
\hline & & & & & & \\
\hline & $\begin{array}{c}\text { Mengalami } \\
\text { vertigo }(\mathrm{n} \%)\end{array}$ & $\begin{array}{c}\text { Tidak } \\
\text { Mengalami } \\
\text { Vertigo (n \%) }\end{array}$ & & & Lower & Upper \\
\hline Ya & $\begin{array}{c}27 \\
(71,1 \%)\end{array}$ & $\begin{array}{c}17 \\
(44,7 \%)\end{array}$ & & & & \\
\hline Tidak & $\begin{array}{c}11 \\
(28,9 \%) \\
\end{array}$ & $\begin{array}{c}21 \\
(55,3 \%) \\
\end{array}$ & 0,020 & 3.032 & 1,174 & 7,831 \\
\hline Total & $\begin{array}{c}38 \\
(50,0 \%)\end{array}$ & $\begin{array}{c}38 \\
(50,0 \%)\end{array}$ & & & & \\
\hline
\end{tabular}

Dari tabel diatas dapat dilihat bahwa Menunjukkan bahwa diabetes melitus 3,0 kali ada hubungan yang bermakna $(\mathrm{p}<0.05)$ antara lebih mempunyai peluang terjadinya vertigo. diabetes mellitus dengan vertigo. Diabetes mellitus merupakan faktor resiko terjadinya c. Hubungan Dislipidemia Dengan Vertigo vertigo dengan odd Ratio 3,032.

Tabel 3. Hubungan dislipidemia dengan vertigo di RSU Anutapura Palu Tahun 2018.

\begin{tabular}{|c|c|c|c|c|c|c|}
\hline \multirow{3}{*}{ Dislipidemia } & \multirow{2}{*}{\multicolumn{2}{|c|}{ Pasien Cerebro-Kardiovaskuler }} & \multirow{3}{*}{$\mathrm{P}$} & \multirow{3}{*}{ OR } & \multirow{2}{*}{\multicolumn{2}{|c|}{$\mathrm{CI}$}} \\
\hline & & & & & & \\
\hline & $\begin{array}{c}\text { Mengalami } \\
\text { vertigo }(\mathrm{n} \%)\end{array}$ & $\begin{array}{c}\text { Tidak } \\
\text { Mengalami } \\
\text { Vertigo (n \%) }\end{array}$ & & & lower & Upper \\
\hline $\mathrm{Ya}$ & $\begin{array}{c}16 \\
(42,1 \%)\end{array}$ & $\begin{array}{c}20 \\
(52,6 \%)\end{array}$ & & & & \\
\hline Tidak & $\begin{array}{c}22 \\
(57,9 \%)\end{array}$ & $\begin{array}{c}18 \\
(47,4 \%)\end{array}$ & 0 & 0,655 & 0,265 & 1,619 \\
\hline Total & $\begin{array}{c}38 \\
(50,0 \%)\end{array}$ & $\begin{array}{c}38 \\
(50,0 \%)\end{array}$ & & & & \\
\hline
\end{tabular}

Dari tabel diatas dapat dilihat bahwa belum dapat dibuktikan ada hubungan yang bermakna ( $>0.05)$ antara dislipidemia dengan vertigo. Dislipidemia bukan merupakan faktor resiko terjadinya vertigo dengan Odd Ratio 0,655 .

Hasil analisis statistik data menggunakan program SPSS versi 22, diperoleh hasil yang bermakna dimana $\mathrm{P}=0,018(\mathrm{p}<0,05)$ sehingga diperoleh kesimpulan bahwa hipertensi merupakan faktor resiko terjadinya vertigo.

Hasil penelitian ini sejalan dengan (Amaliah, 2010) di RSUD Dr. Moewardi Surakarta, yang menyatakan bahwa adanya hubungan antara hipertensi dengan kejadian vertigo, yaitu sebesar $19,7 \%$. Hipertensi dapat 
menimbulkan ketidakseimbanagn ketika terjadi lesi perivaskuler yang mempengaruhi serat sensoris dan motoris yang menghubungkan area korteks dengan thalamus, ganglia basalis, serebelum dan medulla spinalis (Bronstein, 2006). Dimana pengaturan keseimbangan merupakan fungsi gabungan dari bagian serebelum, substansia retikuler dari medulla, pons, dan mesensefalon (Guyton, 1997).

Berdasarkan hubungan diabetes melitus terhadap kejadian vertigo diketahui bahwa sebagian besar pasien mengalami vertigo. Hasil analisis statistik data, diperoleh hasil yang tidak bermakna dimana $\mathrm{P}=0,020$ $(\mathrm{p}<0,05)$ sehingga diperoleh kesimpulan bahwa diabetes mellitus merupakan faktor resiko terjadinya vertigo.

Hasil penelitian ini sejalan dengan (Desnita, R. 2017) di RSUP Dr. M. Djamil, di Padang, yang menyatakan bahwa adanya hubungan diabetes melitus dengan kejadian vertigo, yaitu sebesar 14,5\%. Proses neuropati pada pasien DM menyebabkan terjadinya disfungsi vestibular yang mengatur keseimbangan. Selain itu, Kondisi hiperglikemia pada pasiean diabetes mellitus juga menyebabkan disfungsi vestibular dalam mempertahankan keseimbangan tubuh (D’Silva et al., 2016).

Faktor-faktor Resiko Cerebro-kardiovaskuler Yang Mempunyai Hubungan Tidak Bermakna Dengan Kejadian Vertigo

Dislipidemia didefinisikan sebagai kelainan metabolisme lipid yang ditandai dengan peningkatan dan penurunan dari fraksi lipid dalam plasma. Kelainan fraksi lipid yang utama adalah kenaikan kadar kolesterol total (kol-total), kolesterol LDL, trigliserida , serta penurunan kolesterol HDL. (PERKI, 2013).

Hasil penelitian hubungan dislipidemia terhadap kejadian vertigo diketahui bahwa sebagian besar pasien dislipidemia mengalami vertigo. Hasil analisis statistik data, diperoleh hasil yang tidak bermakna dimana $\mathrm{P}=0,844$ ( $>0,05)$ sehingga diperoleh kesimpulan bahwa dislipidemia belum dapat dibuktikan mempunyai hubungan yang bermakna dengan kejadian vertigo.

Hasil penelitian ini tidak sesuai dengan teori yang ada, kemungkinan disebabkan karena pengambilan data pada penelitian ini harusnya juga dilakukan dengan wawancara dan tes kadar kolesterol total secara langsung tidak hanya dengan melihat pada rekam medic.

\section{KESIMPULAN}

Dari uraian di atas dapat disimpulkan bahwa:

1. Ditemukan hubungan yang bermakna antara hipertensi dengan kejadian vertigo.

2. Ditemukan hubungan yang bermakna antara diabetes mellitus dengan kejadian vertigo.

3. Belum dapat dibuktikan hubungan yang bermakna antara dislipidemia dengan kejadian vertigo.

\section{DAFTAR PUSTAKA}

1. Joesoef A.A., Vertigo. Dalam: Harsono, editor. Kapita selekta neurologi. Yogyakarta: Gadjah Mada University Press. p 341-359.

2. Departemen Kesehatan. 2013.

3. Bashiruddin J. Vertigo posisi paroksismal jinak. Dalam: Arsyad E, Iskandar N, editor. Telinga, hidung tenggorok kepala dan leher. Edisi Ke-6. Jakarta: Balai Penerbit FKUI; 2008. p. 104-190.

4. Sloane P., Blazer D., George L.K. Dizziness in a community elderly population. J Am Geriatr Soc; 2012. 37(2): p 101-108.

5. Chang C.C., Huang C.R., Lin T.K., et al. The Relationship between Isolated Dizziness/Vertigo and the Risk Factors of 
Ischemic Stroke. Acta Neurol Taiwan; 2011. 20: p 101-106.

6. Feigin V.L., Roth G.A., Naghavi, M. Global burden of stroke and risk factors in 188 countries, during 1990-2013: A systematic analysis for the Global Burden of Disease Study 2013. Lancet Neurol; 2016.15(9): p 913-924.

7. El-Tallawy, H.N., Farghaly W.M.A., Shehata G.A. Epidemiology of non-fatal cerebrovascular stroke and transient ischemic attacks in Al Quseir, Egypt. Clin Interventions Aging; 2013. 8: $\mathrm{p}$ 15471551.

8. Cadilhac D.A., Kim J., Lannin N.A. National stroke registries for monitoring and improving the quality of hospital care: A systematic review. Int J Stroke; 2016. 11(1): p 28-40.

9. Ahmad O.B., Boschi-Pinto C., Lopez A.D., et al. Age standardization of rates: A new WHO world standard. Geneva: World Health Organization; 2001.

10. Vaartjes I., O'Flaherty M., Capewell S., et al. Remarkable decline in ischemic stroke mortality is not matched by changes in incidence. Stroke; 2013. 44: p 591-597. 